\title{
Rubén Darío y Shakespeare. Un artículo humorístico desconocido
}

\section{Rubén Darío and Shakespeare. An unknown humorous article}

\author{
Günther Schmigalle \\ Academia Nicaragüense de la Lengua \\ schmigalle2000@yahoo.de
}

\section{RESUMEN}

Presentamos un artículo humorístico desconocido en el cual Rubén Darío, bajo seudónimo, se burla de los estudios shakespearianos y de la erudición históricoliteraria de su tiempo. El texto contiene una prodigiosa cantidad de referencias que indican que el poeta se inspiró en tres libros sobre Shakespeare del autor francés Alfred Mézières. Como introducción ofrecemos un resumen global de las lecturas shakespearianas de Darío.

\section{Palabras clave}

Rubén Darío, William Shakespeare, Alfred Mézières, erudición, sátira.

\section{ABSTRACT}

We present a hitherto unknown humorous article where Rubén Darío, under a pseudonym, makes fun of the Shakespearian studies and the literary-historical scholarship of his time. His article makes a huge number of references which show that he drew inspiration from three books on Shakespeare by the French author Alfred Mézières. As an introduction we present an overview of Darío's Shakespearian readings.

KEYWORDS

Rubén Darío, William Shakespeare, Alfred Mézières, scholarship, satire.

RECEPCIÓN: 05/12/2019

ACEPTACIÓN: 29/01/2020

$\mathrm{E}$ l domingo 22 de julio de 1894, el periódico La Razón de Montevideo presentó en su primera página algunos párrafos del artículo necrológico de Rubén Darío 


\section{| Günther Schmigalle}

sobre Leconte de Lisle, que se había publicado en su forma completa dos días antes, el 20 de julio, en el diario La Nación de Buenos Aires. Tanto el texto de La Nación como los fragmentos de La Razón llevaron la firma RUBÉN DARío. El artículo, acompañado por un retrato de Leconte de Lisle por Malharro en ambos rotativos, conocerá un destino glorioso: llegó a ocupar el primer lugar en la edición prínceps de Los Raros y el tercero en la segunda con sus numerosas reediciones.

En la misma página de La Razón, precediendo inmediatamente los párrafos sobre Leconte de Lisle, se incluyó un artículo hoy olvidado. Bajo el título "El erudito", y firmado "X. Equis", se lee una sátira sumamente divertida de la erudición histórico-literaria en general, y de los estudios sobre Shakespeare en específico. Nuestra hipótesis es que se trata de otro texto de Darío, quien solía publicar sus artículos humorísticos bajo seudónimo. ${ }^{1}$

El rasgo estilístico más marcado del artículo es la enumeración; el lector la encontrará en casi todos los párrafos de "El erudito". Se trata de un procedimiento que Darío emplea en muchos escritos y que le sirve en los contextos más diversos, ya sea para listar a los representantes de la escuela dantesca en España, como en su artículo sobre Mitre:

El señor Amador de los Ríos ha tratado extensamente el asunto, y no tengo espacio para repetir los afanes que en seguir a Imperial pusieron Ruy Páez de Ribera, Diego Martínez de Medina, Fernán Pérez de Guzmán, fray Migir, Juan Alonso de Baena, Pedro Vélez de Guevara, fray Bartolomé García de Córdoba, don Mosseh Aben-Zarzal, Pedro González de Uceda, fray Alonso de la Monja, fray Lope del Monte, y otros tantos que abrieron senda o coadyuvaron al marqués de Santillana y a Juan de Mena, para afirmar el estudio de la literatura italiana y su influencia en nuestras letras (1894: 1);

ya sea para presentar los nombres de los ganadores del Grand Prix, como en un artículo sobre las carreras de caballos en Francia:

Desde 1863, una larga lista señala triunfos sucesivos - tal una enumeración de papas, de reyes ó de generales: The Ranger, Vermont, Gladiateur, Ceylan, Férvacques, The Earl, Glaneur, Sornette, Cremome, Boiard, Trent, Salvator, Kisber, Si Cristope, Thurio, Nubienne, Rovert-Devil, Foxhall, Bruce, Frontin, Little Duck, Paradox, Mintin, Tene-

\footnotetext{
${ }^{1}$ Seis semanas antes, el 4 de junio de 1894, había publicado "El idioma de los monos" bajo el seudónimo Dr. Filosimio en La Nación (cfr. Schmigalle y Caresani: 102-107). Por una curiosa coincidencia, ese 4 de junio de 1894 apareció en La Nación su artículo sobre Laurent Tailhade, quien en aquella época escribía poemas inspirados en los antiguos cantos de la iglesia y, al mismo tiempo, renovó a Rabelais con poesías brutalmente satíricas. Darío había hecho amistad con él en el verano de 1893. ¿Quiso seguir su ejemplo y mostrar que él también podía manejar los dos instrumentos: el solemne en su necrología de Leconte de Lisle, y el humorístico en su entrevista con Rapsodien de Blagenthal?
} 


\section{Rubén Darío y Shakespeare. Un artículo humorístico desconocido}

breuse, Stuart, Vasistas, Fitz Roya, Clamart, Rueil, Ragotski, Dolman Baghtche, Andrée, Arreau, Doge, Le Roi Soleil, Perth, Semandria, hasta el glorioso bruto de ahora, Chéri, cuyo propietario Caillaut no cabe en su orgullo (1902: 40).

El lector, que encontrará, pues, en "El erudito” párrafos como el siguiente:

El examen y el análisis circunstanciado de los trabajos y de la vida de todos estos escritores, no es más que la base general del estudio sobre Shakespeare, á quien he dedicado otras tantas resmas de papel, para los apuntes y las notas que de los comentarios, las interpretaciones y las exégesis de sus obras he tenido que hacer, después de haberme tragado todo lo que se ha publicado desde su tiempo hasta hoy, acerca de su nacimiento, su educación, su vida, sus costumbres, sus aficiones, sus aptitudes, sus inclinaciones, su familia, sus amigos, sus relaciones, sus recursos pecuniarios, sus medios de vida, sus estudios, sus lecturas, sus opiniones, sus trabajos, sus personajes, su estilo, su manera de escribir, etc., etc., etc.,

reconocerá un rasgo estilístico familiar en Darío, con la diferencia de que en sus artículos "serios" nuestro poeta/cronista usa la enumeración para dinamizar su texto y evocar cierto ambiente intelectual, deportivo u otro; mientras que en "El erudito" la enumeración se desboca, aturde y da vértigo, con un efecto cómico seguro.

Para resumir brevemente el artículo, hemos numerado con corchetes sus once párrafos. En el primero, el narrador presenta a los lectores a un amigo suyo, un sabio alemán, Dr. Heriberto Rapsodien de Blagenthal, miembro de un instituto histórico de Berlín, especialista en la historia del verso blanco. Casi todo el texto es una especie de monólogo de este personaje, interrumpido raras veces por alguna pregunta o exclamación del narrador. En el segundo, se nos informa que Blagenthal salió de Alemania hace cinco años, con el fin de compilar, en diferentes bibliotecas del mundo, los materiales para escribir una historia completa de la recepción de la obra de Shakespeare, desde los inicios hasta el día presente. En el tercero, se explica que su estudio abarcará los predecesores, contemporáneos y sucesores del poeta británico, con lo cual se nos remite, implícitamente, a tres libros fundamentales del autor francés Alfred de Mézières: Shakespeare, ses œuvres et ses critiques (1860), Prédécesseurs et contemporains de Shakespeare (1863) y Contemporains et successeurs de Shakespeare (1864). En el mismo párrafo, el erudito alemán comienza a enumerar los predecesores, citando y recitando un número vertiginoso de nombres y de referencias, todas ellas recogidas hábilmente de los Prédécesseurs de Mézières. Después, Blagenthal prosigue con los contemporáneos, incluidos en el segundo volumen del crítico francés. De los párrafos 4 al 9, el baile de cabezas continúa con alusiones a los críticos históricos y coetáneos de Shakespeare y a las fuentes de sus obras, todas tomadas del tercer volumen de Mézières. En el párrafo 9, aparecen algunas menciones - a Victor Hugo, Paul de Saint-Victor, Castelar y Luis Melián Lafinur- que indican que la erudición shakespeariana de 


\section{Günther Schmigalle}

Darío/Blagenthal no se limita a los libros de Mézières. De los párrafos 10 al 14, el artículo concluye con la aclaración de que Blagenthal ha leído "millares y millares" de volúmenes de lo que se suele llamar "estudios históricos y críticos" o también (un poco despreciativo) "literatura secundaria", pero apenas ha "hojeado algunas veces" las obras mismas de Shakespeare.

Llama la atención una acumulación insólita de errores de imprenta: muchísimos nombres propios aparecen desfigurados; asimismo, sorprenden varias contradicciones internas del texto: en el primer párrafo, Blagenthal es "amigo" del narrador, y en el último, se despide de él de manera fría y distante; para compilar la literatura sobre Shakespeare, Blagenthal sale de Alemania, aunque este país, en aquel tiempo, fuese el centro de los estudios shakespearianos; en el primer párrafo, Blagenthal afirma que ya terminó su trabajo, pero al final dice que todavía le falta "completar sus conocimientos históricos relativos a Inglaterra" antes de comenzar a escribir, etc. Esos y otros detalles parecen indicar que el artículo se escribió o dictó con gran rapidez, mientras Darío hojeaba los volúmenes de Mézières. Ciertos errores ("gramática" por "dramática", "ciento ochenta años" por "ochenta años" en el párrafo 3; "magia" por "comedia" en el párrafo 4) hacen suponer, además, que el texto fue dictado y que quien dictaba y quien escribía no se encontraban en un lugar silencioso. El mismo nombre de Heriberto Rapsodien de Blagenthal no se le ocurriría a un escritor plenamente sobrio. Estamos, pues, ante un documento surgido de aquellas reuniones literarias donde "la sobriedad no era nuestra principal virtud" (Darío, 1915: 167), lo cual no excluye que estos aspectos apresurados fueran buscados de manera consciente para contribuir al distanciamiento humorístico.

Las lecturas de Shakespeare están presentes siempre en Darío. Hay que recordar que uno de los puntos de partida del movimiento simbolista fue la veneración de Shakespeare en la Francia decimonónica, especialmente marcada en Catulle Mendès y en Mallarmé. La imagen francesa de Shakespeare fue selectiva; se le consideraba, sobre todo, poeta de reflexiones y de sentimientos. Por eso, no nos puede sorprender que el drama más admirado por Darío, al igual que por los simbolistas, fuese Hamlet, y que el poeta-cronista se molestara cuando la compañía de Sarah Bernhardt representó en Madrid una versión abreviada de la tragedia, en la cual se suprimieron, justamente, dos de las escenas más reflexivas: la oración del Rey y el diálogo de Hamlet y Horacio con los sepultureros (véase Darío, 1998: 295).

Ya en Epistolas y poemas (1885), Europa es para Darío "la tierra de los sabios [...] donde Voltaire rio y habló Cervantes, y nacieron los Shakespeares y los Dantes” (1952: 413). La influencia más fuerte del poeta británico se observa en sus escritos chilenos y argentinos de los años 1887-1893: "El deslumbramiento shakespeariano me poseyó", dice sobre esa etapa de su vida (1988b: 44). En 1887, Darío publicó en La Época de Santiago su cuento "El velo de la reina Mab", que incluyó después en Azul... En las 


\section{Rubén Darío y Shakespeare. Un artículo humorístico desconocido}

notas a la edición guatemalteca de $A z u l . .$. , reproducida como facsímile en Nicaragua, explica que "La reina Mab es una de las creaciones de la mitología inglesa. Es la reina de los sueños. Shakespeare se refiere a ella, por boca de Mercutio, en la escena IV del acto I de Romeo y fulieta", y cita el discurso de Mercutio en la traducción de Menéndez Pelayo (1988a: 373-375). Ernesto Mejía Sánchez ha identificado la edición citada: Dramas de Guillermo Shakespeare: El mercader de Venecia; Macbeth; Romeo y Julieta; Otelo. Barcelona: Biblioteca Arte y Letras, 1881 (véase Darío, 1993: 124, nota 34). En 1888, para defender a su amigo Pedro Nolasco Préndez, acusado por plagio, Darío escribe en La Época de Santiago de Chile: "Shakespeare, el gran Shakespeare tiene en su poema Venus y Adonis, por ejemplo, pensamientos expresados con las mismas palabras de uno de los bucólicos griegos" (1934: 259); y en una carta dirigida al mismo amigo, alude a la controversia sobre la autoría de las obras de Shakespeare (2000: 93), puesta al día por Donnelly en su libro The Great Cryptogram, que tomará un giro inesperado pocos años después de la muerte de Darío. ${ }^{2}$ Diversos textos publicados en Buenos Aires en 1893 reflejan también la lectura de Shakespeare: "El linchamiento de Puck", "La miss" con sus referencias a Ofelia (1993: 254-255, 259-262), "Fin de cuento" con sus citas de Romeo y fulieta, y "Get Thee to a nunnery" con varias más "del misterioso príncipe de Dinamarca" y otra de Otelo (1938: 7-8, 9). Por tal motivo, Mejía Sánchez pudo comentar: "El conocimiento de Shakespeare que alcanzó Darío en sus primeros años, a través de las traducciones de José Arnaldo Márquez y Menéndez y Pelayo, llega por esta época a los textos originales" (Darío, 1993: 260, nota 128). Llama la atención que, en esa etapa, lo que más fascinaba a Darío fueran los discursos violentos y misóginos de Hamlet y, en especial, su maltrato verbal hacia la inocente Ofelia. Se trata, posiblemente, de un reflejo de dos experiencias de la vida amorosa del poeta: la traición, en 1886, de su novia Rosario Emelina Murillo cuando permitió que su madre la entregara, por una suma considerable de dinero, a Pedro Joaquín Chamorro Alfaro, expresidente de Nicaragua, que moriría pocos años después y a quien Darío llama, en otro contexto, "un anciano granadino, calvo, conservador, rico y religioso" (1915: 43); y el matrimonio forzado que, el 8 de marzo de 1893, los hermanos de Rosario impusieron al poeta a punta de revólver (el primero de los dos dramas se refleja en Abrojos, y ambos se describen en El oro de Mallorca). ${ }^{3}$

${ }^{2}$ Donnelly creía que las obras atribuidas a Shakespeare fueron escritas por Francis Bacon. Después de la muerte de Darío, surgieron otros candidatos: William Stanley, VI ${ }^{\mathrm{e}}$ comte de Derby y, el más serio de todos, Edward de Vere, $17 .^{\circ}$ conde de Oxford (véanse Lefranc; Looney; Groussac).

${ }^{3}$ Escribe Darío: "la mayor desilusión que pueda sentir un hombre enamorado" (1915: 60); "el caso más novelesco y fatal de mi vida" (1915: 139); "ello fue el encontrar el vaso de sus deseos poluto" (2017: 408), "una escena de folletín [...] melodrama familiar" (2017: 409). Véase también Torres (141-143, 299-300, 310). Arellano afirma que no existió el "revólver intimi- 


\section{Günther Schmigalle}

En 1893, en su artículo sobre Jean Moréas, después incluido en Los Raros, Darío cita un verso del soneto $n^{\circ} 138$ de Shakespeare:

When my love swears that she is made of truth

y tres versos de The Phoenix and Turtle:

Beauty, truth and verity

Grace in all simplicity

Here enclosed in cinders lie (2015: 88).

A Leconte de Lisle lo compara con Dante, Shakespeare y Milton (2015: 269), a Villiers de l'Isle Adam le certifica que "solamente un soplo de Shakespeare hubiera podido hacer vivir, respirar, obrar de ese modo, al tipo estupendo que encarna nuestro tiempo", a saber, Tribulat Bonhomet (2015: 202). En su texto sobre Rachilde, cita otro verso de un soneto de Shakespeare:

A woman's face, with nature's own hand painted... (2015: 298)

A Ibsen lo llama "hermano de Shakespeare" y se refiere al libro de Léon Daudet, Le voyage de Shakespeare (1896), para afirmar que "el proceso shakespeareano de León Daudet tendría mejor aplicación si se tratase del gran Escandinavo" (2015: 374). En las "Palabras liminares" a Prosas profanas (1896), proclama los nombres de sus grandes modelos: “¡Shakespeare! ¡Dante! ¡Hugo...! (Y en mi interior: ¡Verlaine!)” (1984: 13). Y también, en 1896, en su artículo sobre Mark Twain: "Mas en toda su obra no hallaréis esa inmensa y vaga melancolía que llega a veces a lo trágico, y que se desprende del humor inglés desde el día en que el príncipe Hamlet tomó en sus manos la calavera de Yorick" (1938: 97-98).

En su artículo sobre Poe, publicado en la Revista Nacional de Buenos Aires y también incluido en Los Raros, abundan las referencias a la Tempestad. Es cierto que para esa fecha la identificación de Calibán con los Estados Unidos se había vuelto un lugar común en los círculos intelectuales de Buenos Aires (Gewecke: 66, nota 34), pero las frases de Darío indican una familiaridad especial con el texto shakespeariano:

Calibán reina en la isla de Manhattan, en San Francisco, en Boston, en Washington, en todo el país. [...] Calibán se satura de whiskey, como en el drama de Shakespeare de vino; se desarrolla y crece; y sin ser esclavo de ningún Próspero, ni martirizado por ningún genio del aire, engorda y se multiplica; su nombre es Legión. Por voluntad de Dios suele

dante" (37), a pesar de lo que dice Edgardo Prado en su fundamental artículo: "el hermano de la señora, Andrés, pistola en mano, hizo celebrar la ceremonia" (4-B). 


\section{Rubén Darío y Shakespeare. Un artículo humorístico desconocido}

brotar de entre esos poderosos monstruos, algún ser de superior naturaleza, que tiende las alas a la eterna Miranda de lo ideal. Entonces, Calibán mueve contra él a Sicorax; y se le destierra o se le mata. [...] Poe, como un Ariel hecho hombre, diríase que ha pasado su vida bajo el flotante influjo de un extraño misterio (2015: 111-112, 116).

Darío indica una de sus fuentes: “esos feroces calibanes...' escribe Peladan”, y pregunta: "¿Tuvo razón el raro Sar al llamar así a estos hombres de la América del Norte?" (2015: 111). Lo que dice Péladan en su Queste du Graal es: "Caliban règne dans toute l'île; ses fils ont eu des fils, atroces et sans Dieu" (35). Darío, citando de memoria, cambia "atroces" por "feroces" y nombra la isla: "Calibán reina en la isla de Manhattan” (2015: 111). La metáfora tuvo mucho éxito: dos años después de Los Raros, en El Tiempo de Buenos Aires, Darío publicó su artículo "El triunfo de Calibán” (1938: 160162; 1989: 161-166), y en 1900 apareció el famoso Ariel de José Enrique Rodó. "Dos años antes que Rodó lo hiciera; Darío - un Darío de 1898, visto tradicionalmente como el escapista y esteta de la 'torre de marfil'- usaba con una retórica frontal la oposición Ariel/Calibán en su condena a los Estados Unidos, a propósito de la guerra de Cuba", comenta un crítico perspicaz (Jáuregui: 442).

A partir de su traslado a España y a Francia, las referencias de Darío a Shakespeare se mantienen constantes, pero su enfoque cambia. En noviembre de 1899, en Madrid, escribe su artículo "Tenorio y Hamlet" (1998: 292-298). Ernesto Gutiérrez explica: "Este artículo está consagrado a comentar las representaciones del Don Juan por Thuiller y de 'Hamlet' por Sarah Bernhardt [...] Se ve en estos comentarios que Rubén vivía atento a la puesta en escena de las obras shakespearianas en los teatros de Europa" (31). Y Darío comentó el drama con mucha emoción: "en las partes básicas de la tragedia, el encanto aportado por Sarah vale por una de las más inmensas sensaciones de arte que puedan experimentarse" (1998: 295).

En 1901, al hablar del rey Eduardo VII en una crónica escrita en Londres, cita dos veces el drama histórico Enrique $I V$, traducido al español por Miguel Cané - Darío cita la versión original inglesa - (1902: 82-83; 2010: 290-298). En otra crónica del mismo año, sobre la visita del zar a Francia, cita Richard III: "Death and destruction dog thee at the heels" (1902: 106). En 1903, puso el título "Shakespeare de última hora" a un artículo sobre el golpe de estado en Serbia que terminó con el reinado y la vida de Alejandro Obrenović y Draga Mašin (1907: 85-92), evocando las masacres con que suelen finalizar las tragedias de Shakespeare y de otros autores dramáticos de la época isabelina. En 1904, en un artículo sobre la literatura y la cocina, afirma que "Shakespeare es maravilloso cuando habla de cosas de comida" (2006: 329), lo cual parece exagerado; pero la verdad es que, recientemente, una serie de críticos se han dedicado a explorar las metáforas culinarias del poeta británico (Albala: 63), a veces más macabras que maravillosas: 
Hark, villains! I will grind your bones to dust And with your blood and it I'll make a paste, And of the paste a coffin I will rear And make two pasties of your shameful heads (Titus Andronicus, acto 5, escena 2).

En 1904, en Gibraltar, observa "a Shylock, junto a un sórdido mostrador, un Shylock como el que hace Novelli, todo vestido de negro" (2001: 105). En 1905, en Cantos de vida y esperanza, encontramos el verso "¡oh Shakespeare pobre, y oh Cervantes manco!" (2005: 77). En 1906, en el Hipódromo de Londres, una cabeza parlante llamada Dronza contesta preguntas "con voz bronca y profunda", y Darío comenta: "Tal la oiría Hamlet de su padre" (2011: 17). En 1909, en Viaje a Nicaragua, se defiende contra "quienes critiquen la preferencia en nuestras zonas por princesas ideales o legendarias, por cosas de prestigio oriental, medioeval, Luis XIV, o griego, o chino". Y argumenta: "Homero, señores míos, tenía sus lotófagos; Shakespeare, su Italia, o su Dinamarca, o su Roma, y, sobre todo, sus islas divinas" (1987: 199). El mismo año, una crónica suya con el título "Shylock contra Shakespeare" resume el eterno resentimiento de los escritores contra los editores que explotan su trabajo (2011: 115-117). En 1911, Darío recuerda algunos de los famosos aforismos de Jean Moréas, entre ellos, una definición poco respetuosa de la personalidad de Blaise Pascal: "Es una especie de Shakespeare; solamente le faltaba guardar los caballos a la puerta del teatro, como el Inglés" (2011: 381). En 1909, Jacinto Benavente es "el Shakespeare de los niños" (2011: 199); en 1910, Aubrey Beardsley es "hermano de Laforgue, hijo de Shakespeare" (2011: 303); y en 1911, "El Pájaro azul" de Maeterlinck es "sencillo y shakespeariano" (2011: 393). En 1910, a bordo del "Champagne", las nubes sobre el Atlántico le recuerdan palabras de Polonio (2011: 307); en 1912, a bordo de otro barco, un gordo simpático le evoca a Julio César, y reflexiona: "Si Bruto hubiera sido gordo, no hubiera asesinado a su bienhechor" (2011: 432). En abril del mismo año, publica "Shakespeare en la política hispano-americana" en La Nación (1968: 235-237), que comienza con la frase: "Tenemos entendido que, después de la creación de Dios, está la creación de Shakespeare". Se trata del resumen de un artículo del autor mexicano David Cerna, en el cual se destacan numerosas analogías entre la vida de Bernardo Reyes, general mexicano a quien frecuentaba Darío durante su exilio en París, y el Coriolanus de la tragedia de Shakespeare. En julio de 1909, escribe en "Algunas notas sobre Valle Inclán”:

Guando Octave Mirbeau descubrió en el Figaro parisiense á Maeterlinck, nombró á Shakespeare, Hugo, si no me engaño, en una breve frase, rememoró al omnividente Will, á propósito de las extraordinarias niñerías de Rimbaud [...] Los personajes que en su ya larga serie de obras ha creado este espíritu de excepción, son vivientes más allá de la real vida, más allá de la vida normal; no existen como los héroes balzacianos ó zolescos, sino como Hamlet, Otelo, ó el viejo Lear (1912: 60). 


\section{Rubén Darío y Shakespeare. Un artículo humorístico desconocido}

Con "El erudito", regresamos a la etapa revolucionaria del joven poeta. Se puede deplorar que Darío haya tratado de la erudición shakespeariana en un texto satíricohumorístico y no de manera más seria, pero eso no significa que despreciara ese tipo de estudios, al contrario: recordemos que, en su artículo sobre Prosas profanas y los inicios de la revolución modernista, insiste en "el valor del estudio y de la aplicación constante", subraya que "era preciso la base del conocimiento del arte a que uno se consagraba, una indispensable erudición y el necesario don del buen gusto", y agrega que "para realizar la obra de reforma y de modernidad que emprendiera, he necesitado anteriores estudios de clásicos y primitivos" (1988b: 59 y 73). En Azul... realza la "aplicación de la erudición oportuna" (1988b: 48-49). En cuanto a Shakespeare, en el texto citado "Shakespeare en la política hispano-americana", demuestra su propia erudición con referencias a varios críticos shakespearianos, entre ellos, Edward Dowden, Henry Norman Hudson y Barrett Wendel. Lo que sí le debe haber molestado es el hecho de que Mézières, en sus tres libros, diera más espacio a los predecesores, contemporáneos y sucesores de Shakespeare que a sus obras mismas: según Darío, no hay ni que cortarlo o descuartizarlo (1998: 295), ni ahogarlo en su contexto histórico. De cualquier modo, aparte de su valor intrínseco de lectura instructiva y divertida, el artículo merece ser rescatado como un documento que forma parte de la faceta humorística de Darío, de sus lecturas amplias, y a veces heterodoxas, y de su infatigable combate contra el "anquilosamiento académico" (1915: 196). A continuación, reproducimos el texto tal como aparece en el periódico, con sus acentos no aceptados hoy, con sus faltas de los primeros signos en las interrogaciones y en las exclamaciones, las comas mal colocadas, etc. El lector que preste atención a esos detalles no sólo leerá el texto, sino que percibirá también algo de las circunstancias de su producción original. Las referencias en las notas a pie permiten seguir el proceso mediante el cual Darío asimiló, condensó y parodió sus fuentes, en este caso los tres volúmenes de Alfred Mézières.

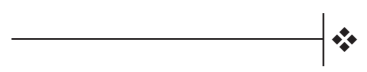





\section{El erudito ${ }^{1}$}

\section{$\mathrm{X}$. Equis}

[1] — Por fin he terminado! — dijo tomando asiento frente á mi butaca, en otra cuyos brazos abiertos parecían salirle al encuentro, - mi erudito amigo el doctor Rapsodien de Blagenthal, miembro activo del Instituto de Escavaciones Históricas que tiene su asiento en Berlín, y corresponsales incansables en todas [sic] los rincones del mundo donde las piedras provenientes de los escombros que el vulgo ignorante desprecia, suministran á la insaciable curiosidad de los sabios, materia inagotable de incomensurables estudios - el doctor Heriberto Rapsodien de Blagenthal, á quien sus profundas, por no decir hondas investigaciones acerca de la historia racional y cronológica del verso blanco, desde los tiempos más remotos hasta nuestros días, han hecho tan célebre, como al no menos ilustrado, original y castizo historiador checo, don Juan Rodolfo Cestas, ${ }^{2}$ sus fresquísimos cuadros de historia contemporánea; tan contemporánea como dice uno de sus más envidiosos críticos, que casi puede pasar por no acontecida.

[2] He concluido, prosiguió, haciendo con la mano un gesto de tragedia antigua - y sin embargo, tendré que empezar de nuevo la ardua, pero gloriosa tarea que el deseo de ser útil á mis semejantes ha impuesto á mis persistentes aficiones científicas y literarias... Sí, amigo mío; la obra que sin darme, tal vez, exacta cuenta de las dificultades que tengo que vencer he emprendido hace cinco años, (los mismos que cuento de residencia fuera de mi patria - la meditabunda Alemania) - no es tan fácil llevarla a cabo, como cualquier periodista improvisado podría atrevidamente imaginarlo; pues ha de saber usted que me he propuesto escribir sobre Shakespeare y su teatro, un libro que en sus páginas resuma, amplíe y desarrolle todo lo que hasta el día, desde la representación de su primera pieza en Londres, se ha dicho del gran trágico inglés en todos los países de la tierra donde sus obras han sido traducidas; estudiadas, imitadas, comentadas, criticadas y elogiadas.

[3] Para dejar terminado ese trabajo colosal no hago, hace sesenta meses justos, sino leer y tomar apunte de lo que leo, en cuanta biblioteca pública ó privada hallo á mi alcance, á mi paso por las ciudades que con ese esclusivo objeto he empezado á visitar y voy visitando. Ya he llenado de notas sobre los predecesores, los contemporáneos y los sucesores del incomparable poeta, ${ }^{3}$ más de doscientos cuadernos de 500 hojas cada uno.

\footnotetext{
${ }^{1}$ X. Equis [Rubén Darío], "El erudito”, en La Razón. Montevideo (22 de julio de 1894), 1.

${ }^{2}$ Personaje no identificado.

${ }^{3}$ Referencia a los tres libros de Alfred de Mézières: Shakespeare, ses œuvres et ses critiques; Prédécesseurs et contemporains de Shakespeare y Contemporains et successeurs de Shakespeare (véase Bibliografia).
} 


\section{Equis [Rubén Darío]}

En ellos he consignado pacientemente el resultado de mis investigaciones acerca de los orígenes de la gramática $[s i c]^{4}$ inglesa, cuya historia empieza después de los misterios de la Edad Media, como en todas partes, con las farsas y de las moralidades ${ }^{5}$ que fueron el primer síntoma literario de los reinados que tanto brillo han dado á las letras de aquel país, hasta llegar á la época en que la decadencia del arte en general se manifiesta con el triunfo del puritanismo. ${ }^{6}$ El estudio que debo hacer de aquel período, sin el cual no es posible comprender á Shakespeare, me ha obligado á leer los mil quinientos y tantos volúmenes que encierran todo lo que, el ingenio dramático produjo en Inglaterra en ciento ochenta años de incesante actividad: ${ }^{7}$ los intermedios de John Heywood, las farsas de Still, las improvisaciones de Tarleton, Robert Wilson y Kempe; ${ }^{8}$ las traducciones ó imitaciones de los trágicos griegos y latinos hechas por Jasper Heynood [sic], Neryle [sic], Studtley [sic], Nouce [sic], Newton, Gasrigne [sic], Kinwelmarsh, Shackville [sic], Vilmont [sic], Sidney, Whetstone, Edwards, Daniel, la condesa de Penbroke [sic], Brandon, ${ }^{9}$ John Lily [sic], el creador del eufuismo, ${ }^{10}$ Peele y Nash; los dramas anónimos de siglo Xvi; el teatro burgués y al mismo tiempo fantástico de Marlowe, ${ }^{11}$ Ladge [sic],

\footnotetext{
${ }^{4}$ Quizás: ¿la dramática inglesa?

${ }^{5}$ Misterios, farsas, moralidades (Mézières, 1881: 6).

${ }^{6}$ Triunfo del puritanismo: “Ainsi le théâtre en Angleterre n'a été vraiment fécond et florissant que depuis l'avènement d'Élisabeth jusqu'au moment où les puritains, vainqueurs de Charles $\mathrm{I}^{\mathrm{er}}$ et de la royauté, interdirent dans toutes les villes les représentations dramatiques, fermèrent les salles de spectacle et supprimèrent, par un décret, toute une branche de la littérature, aussi facilement que l'Inquisition en Espagne arrêtait tout essor littéraire" ["De esa manera, el teatro en Inglaterra ha sido realmente fecundo y floreciente únicamente desde la subida al trono de Isabel hasta el momento en que los puritanos, después de vencer a Carlos I y a la monarquía, prohibieran en todas las ciudades las representaciones dramáticas, cerraran los teatros y abolieran, por decreto, toda una rama de la literatura, tan fácilmente como la Inquisición en España puso fin a cualquier desarrollo literario"] (Mézières, 1881: 3; las traducciones incluidas en las notas del presente rescate son mías).

7 "Ciento ochenta años": Mézières habla, más bien, de "ochenta años", "período [...] que se extiende de 1560 a 1640", "corta pero gloriosa historia" del arte dramático en Inglaterra durante los tres reinados de Isabel, de Jaime I y de Carlos I (Mézières, 1881: 2-3).

${ }^{8}$ Sobre John Heywood, John Still, Richard Tarleton, Robert Wilson y William Kempe: Mézières, 1881: 27-37.

${ }^{9}$ Sobre Jasper Heywood, Alexander Nevyle, John Studley, Thomas Nuce, Thomas Newton, George Gascoigne, Francis Kinwelmarsh, Thomas Sackville, Robert Wilmot, Philip Sidney, George Whetstone, Samuel Daniel, Mary Sidney Herbert (segunda condesa de Pembroke) y Samuel Brandon: Mézières, 1881: 40-52. No se conoce ningún autor dramático llamado Edwards, aunque sí un poeta lírico (Richard Edwards) y un poeta narrativo (Thomas Edwards). Ninguno de ellos es mencionado en el libro de Mézières.

${ }^{10}$ Sobre John Lyly y el eufuismo: Mézières, 1881: 55-91.

${ }^{11}$ Sobre George Peele, Thomas Nash, los dramas anónimos y Christopher Marlowe: Mézières, 1881: 88-144.
} 
Sreene [sic], Thomas Kyd y Chettle; las comedias clásico-románticas de Ben-Jonson; ${ }^{12}$ las piezas insignificantes de Marston, Dekker, ${ }^{13}$ Beaumont, Fletcher ${ }^{14}$ Middleton, Field, William y Samuel Glapthorne, Daborne, Chapman, Webster, el más sombrío de los dramaturgos de su tiempo; John Robert Taylor; las tragedias impregnadas de sentimiento religioso, y las comedias satíricas de Massenger [sic], Thomás Randolfh [sic] y Ford; las obras llenas de detalles curiosos sobre el mecanismo del antiguo teatro inglés, de Richard Brone [sic]; las casi incomprensibles de Cartwright, Cox, Harlington [sic], Machio [sic] y Tourneur; los dramas parlamentarios de May; los realistas de Suckling, Marmion y Sherloy [sic] que fue el último autor dramático que pudo hacer representar sus producciones en el teatro que los puritanos cerraron en 1642, si no me equivoco. ${ }^{15} \mathrm{El}$ examen y el análisis circunstanciado de los trabajos y de la vida de todos estos escritores, no es más que la base general del estudio sobre Shakespeare, á quien he dedicado otras tantas resmas de papel, para los apuntes y las notas que de los comentarios, las interpretaciones y las exégesis de sus obras he tenido que hacer, después de haberme tragado todo lo que se ha publicado desde su tiempo hasta hoy, acerca de su nacimiento, su educación, su vida, sus costumbres, sus aficciones [sic], sus aptitudes, sus inclinaciones, su familia, sus amigos, sus relaciones, sus recursos pecuniarios, sus medios de vida, sus estudios, sus lecturas, sus opiniones, sus trabajos, sus personajes, su estilo, su manera de escribir, etc., etc., etc.

[4] Puedo repetirle de memoria los argumentos más insignificantes en pro y en contra de la autenticidad de las célebres notas manuscritas que Payne Collier pretende haber descubierto en 1849 en una antigua edición de las obras del poeta; los célebres ataques de Singer, Chales [sic] Wright, Dyce, Delins [sic], White y Halmiton [sic], contra aquel lexicógrafo; ${ }^{16}$ las investigaciones de Malone, Heninge [sic], Condell, Furniwell y Mis [sic] Lee, para quienes solo las dos últimas partes de Enrique IV son de Shakespeare; ${ }^{17}$ los estudios de Gervinus (4 volumenes en $8 .^{\circ}$ ); los de Kreyssig, Taine, Halliwell y Emerson; ${ }^{18}$

\footnotetext{
${ }^{12}$ Sobre Thomas Lodge, Robert Greene, Thomas Kyd, Henry Chettle y Ben Jonson: Mézières, 1881: 161-364.

${ }^{13}$ Sobre John Marston y Thomas Dekker: Mézières, 1881: 197-199.

${ }^{14}$ Sobre Francis Beaumont y John Fletcher: Mézières, 1864: 21-211.

${ }^{15}$ Sobre Thomas Middleton, Nathaniel Field, Henry Glapthorne, Robert Daborne, George Chapman, John Webster, Philip Massinger, John Ford, Thomas Randolph, Richard Broem, William Cartwright, Robert Cox, William Habington, Lewis Machin, Cyril Tourneur, Thomas May, John Suckling, Shackerley Marmion y James Shirley: Mézières, 1864: 287-378. Glapthorne se menciona brevemente en la página 298; Rubén Darío le antepone los nombres de otros dos autores, Samuel y William Rowley (296). John y Robert Taylor fueron dos autores distintos (297), el poeta nicaragüense los fusiona en uno solo.

${ }^{16}$ Las controversias sobre la validez de los hallazgos de Payne Collier se describen en Mézières (1882: V-VI). Esa polémica continúa todavía (Freeman, 2004).

${ }^{17}$ Los debates sobre la unidad de Enrique IV se presentan en Mézières (1882: 78-79).

${ }^{18}$ Gervinus, Kreyssig, Taine, Halliwell y Emerson (Mézières, 1882: VII).
} 


\section{Equis [Rubén Darío]}

las opiniones que le atribuyen en Alemania las escuelas espiritualista, panteísta, realista, monista, evolucionista, y pesimista, por boca de Rosencranz, Vischer, Rötscher, ${ }^{19}$ Ulrice [sic], Elze y Etner [sic], ${ }^{20}$ que ha escrito la historia circunstanciada de las transformaciones por que ha pasado la fábula de Troida [sic] y Cresida, antes de la representación de la célebre magia $[s i c]^{21}$ del mismo nombre; lo que han dicho de él Villemain, Staffer [sic], Darmesteter y Halter [sic] Bracebridge, á cuya erudición debemos un libro de 66 páginas destinado á probar que es falso el testimonio de los que acusan al gran poeta de haber matado un gamo, "delito grave que el dramaturgo no ha cometido",;2 las críticas de Kroenig [sic], Coleridge, ${ }^{23}$ y Brown; los pacientes análisis de Lichtenberger sobre las dedicatorias de los Sonetos; ${ }^{24}$ las polémicas de Drake y Ingleby, las monografias de Furnivall, uno de los representantes de la escuela filológica que ha creído hallar el medio de determinar la fecha de las obras de Shakespeare, siguiendo en ellos la disminución de los versos con rima; ${ }^{25}$ de Davden [sic], que tantas dudas ha disipado sobre la cronología de su teatro; ${ }^{26}$ de Büchner, que ha escrito la historia de las fuentes en que el amigo de Burbadge, ${ }^{27}$ buscaba los argumentos de sus dramas. ${ }^{28}$ Yo también he ido á beber en esas fuentes los datos complementarios de las indagaciones de aquel autor, trabajo que me ha proporcionado la ocasión de conocer á muchos de los personajes de su repertorio, en

${ }^{19}$ Sobre el "Shakespeare enigmático" de las escuelas espiritualistas, panteístas y realistas de Alemania y las obras de Rosencranz, Vischer y Rötscher: Mézières, 1882: VIII. Las escuelas monista, evolucionista y pesimista fueron agregadas por Darío.

${ }^{20}$ Ulrici, Elze y Etner (Mézières, 1882: XV-XVI; 410-411, en nota; 502, en nota).

${ }^{21}$ ¿Por: comedia?

22 Villemain, Stapfer, Darmesteter y C. Holte Bracebridge (Mézières, 1882: XV-Xvi; 13-14). Shakespeare no deerstealer, por C. Holte Bracebridge (Londres, 1862), es un folleto de 32 páginas.

23 "Coleridge se plaint que les yeux de Gloster soient arrachés sur la scène" (Mézières, 1882: 358). "Les fameuses leçons de Coleridge, en 1814, ne furent que le développement des idées qui circulaient depuis longtemps dans la patrie de Lessing [...] Coleridge's Lectures on Shakspeare" ["Las famosas conferencias de Coleridge del año 1814 fueron solamente una ampliación de ideas que circularon desde hacía tiempo en la patria de Lessing [...] Las Lectures on Shakspeare de Coleridge"] (Mézières, 1882: 479-480 y nota 1. Véase Fruman: 141-161).

${ }^{24}$ Ernest Lichtenberger explicó la dedicatoria de los sonetos de Shakespeare en una tesis redactada y publicada en latín: De Carminibus Shakesperi cum nova Thorpianae inscriptionis interpretatione (Mézières, 1882: 104, en nota).

${ }^{25}$ Sobre la escuela filológica de Frederick James Furnivall: Mézières, 1882: 113.

26 "Ni M. Dowden, ni M. Furnivall, ni M. W. Kœnig, trois des critiques les plus récents et les plus autorisés, n'ont pu se mettre d'accord sur tous les points" [“Ni el señor Dowden, ni el señor Furnivall, ni el señor W. Kœnig, tres de los críticos más recientes y más autorizados, han podido ponerse de acuerdo en todos los puntos"] (Mézières, 1882: 114).

${ }^{27}$ Richard Burbadge, el mejor actor de la época (Mézières, 1882: 57-58).

${ }^{28}$ Alexander Büchner (1827-1904), escritor francés de origen alemán, uno de los pioneros de la literatura comparada, estudió las fuentes de Hamlet (Mézières, 1882: 394). 
las novelas, romances y cuentos de los verificadores [sic] y prosistas italianos del siglo XV; de Masuccio, Luigí da Porto, Bandello, Guidodalle Colone [sic $; ;^{29}$ en los escritos de los cronistas bárbaros del norte de Europa como Saxo Gramaticus $[s i c],{ }^{30}$ padre espiritual de Hamlet; en los "Ensayos" de Montaigne, muchos de cuyos pensamientos revoletean en los labios de los cortesanos que desembarcan en la isla donde se desarrolla la Tempestad; en las "Vidas Paralelas" de Plutarco, que es el autor directo de las escenas culminantes de Fulio César, Antonio y Cleopatra, Corilano [sic], Pericles y Timon de Atenas. ${ }^{31}$

[5] Son evidentes, y yo los he constatado después de Vichoft [sic], de Barbier y de Beaussire, ${ }^{32}$ la estrecha relación que existe entre muchos de los caracteres pintados por el primero de los historiadores de la antigüedad, y los tipos que han hallado en el cerebro del más grande creador de almas que los anales de la literatura registran, la verdadera fórmula de sus virtudes, ó de sus vicios. No ha sido poco el tiempo que he tenido que dedicar también á otros autores menos célebres ó notables, y entre los cuales figuran Lydgate, Coxton [sic], imitador de Raul Le Febre [sic], Chauser [sic], ${ }^{33} \mathrm{y}$ los poemas y romances florentinos y provenzales, traducidos al inglés por estos y otros poetas, que fueron los que suministraron á los dramas románticos de Shakespeare, abundante y variado tema.

[6] Para completar mis estudios sobre la índole de sus creaciones he tenido también que averiguar, consultando á los autores del siglo Xvi que han escrito sobre otras materias, hasta que punto están de acuerdo los conocimientos que ellos revelan, con la física, la química, la astronomía, la mecánica, la matemática, la geografía, la historia natural y la política de su tiempo.

[7] - Usted conoce, por supuesto, todas esas ciencias!

[8] - Todas no, pero que importa! Este último estudio sobre todo me ha dado mucho trabajo, pues se adelantaban tanto á su siglo las opiniones que acerca de algunos de

${ }^{29}$ Masuccio, Luigi da Porto, Bandello, Guido delle Colonne, narradores italianos que inspiraron a Shakespeare (Mézières, 1882: 329, 501).

${ }^{30}$ Saxo Grammaticus, cronista danés que cuenta la historia de Hamlet (Büchner: 3).

31 "Ce n'est ni Tite-Live ni Tacite qui lui ouvrent les portes de la cité romaine; il y entre avec Montaigne et avec Plutarque, qui semblent avoir été, pendant quelques années, ses auteurs favoris, et qui lui donnent plus de renseignements sur les hommes que sur les choses" ["No fueron ni Tito Livio ni Tácito quienes le abren las puertas de la ciudad romana; más bien, se introduce en ella con Montaigne y con Plutarco, quienes, según parece, fueron durante algunos años sus autores preferidos y le brindaron más enseñanzas sobre los hombres que sobre las cosas"] (Mézières, 1882: 420).

${ }^{32}$ Henri Viehoff, Auguste Barbier y Émile Beaussire (Mézières, 1882: 429, en nota; 461, en nota).

${ }^{33}$ Lydgate, Caxton, Raoul Le Fèvre y Chaucer (Mézières, 1882: 500-501). 


\section{Equis [Rubén Darío]}

estos ramos del saber humano el gran dramaturgo profesaba, que un sabio alemán ha constatado entre los sucesos de 1848 en Francia y el drama Ricardo II, grandes puntos de contacto! Lo que él pensaba de los acontecimientos contemporáneos que muchas de sus obras reflejan veladamente ó no, ha dado vasto tema á la crítica inglesa de los siglos XVII y XVIII representada, de un lado por Evelyn, Samuel Pepys, Dryden, Pope, que no lo elogian mucho; del otro por Addison y Otway, sus admiradores.

[9] A unos y á otros he leído con cuidado para completar así los apuntes para la historia cronológica de las opiniones que sobre sus obras se han emitido, y de la cual forman parte las de los grandes literatos de los siglos anteriores y del presente. Allí verá Vd lo que han pensado y piensan de él Diderot[,] Goethe, Slelegel [sic], Leessing [sic], Voltaire, Guizot, Philarete Chasle [sic], Mezières, Víctor Hugo, ${ }^{34}$ Montegut, Paul de Saint Victor, ${ }^{35}$ Villemain, Melian Lafinac [sic], ${ }^{36}$ Saint Marc Gardini [sic], ${ }^{37}$ Macauley, Castelar ${ }^{38}$ y tantos otros. A todo esto hay que agregar el estudio del carácter de los diversos pueblos antiguos y modernos que personificados en diversos personajes, figuran en sus dramas, desde el hebreo representado por Shylock, ${ }^{39}$ hasta el italiano sintetizado en Yago según Macauley; ${ }^{40}$ las costumbres que á cada uno de ellos corresponden;

${ }^{34}$ Sobre Goethe, Lessing, Voltaire, Guizot, Philarète Chasles y François-Victor Hugo: Mézières, 1882: XIII, 261, 362, 420, 533-567). François-Victor Hugo (1828-1873) fue el cuarto de los cinco hijos de Victor Hugo y Adèle Foucher. Su traducción francesa de las obras de Shakespeare se publicó en 18 tomos entre 1859 y 1866. Pero quizás Darío/Blagenthal aluden al William Shakespeare de Victor Hugo, que apareció en 1864.

${ }^{35}$ Se refiere, sin duda, al tercer tomo de la obra de Paul de Saint-Victor, Les Deux masques, que lleva el subtítulo: Les Modernes: tragédie-comédie: Shakespeare, le théâtre français depuis ses origines jusqu’à Beaumarchais, en el que habla de Shakespeare en las páginas 3-185. Mézières no podía conocer esta obra, publicada en 1884; así que Darío/Blagenthal deben haber tomado el dato de otra fuente.

${ }^{36}$ Luis Melián Lafinur (1850-1939), uruguayo, autor de Las mujeres de Shakespeare (Montevideo: Rius, 1884).

37 "M. Saint-Marc Girardin a étudié, avec la pénétration et la justesse habituelles de sa critique, le caractère de Porcia (De l'amour conjugal dans Shakespeare, Magasin de librairie, t. VIII)" ["El señor Saint-Marc Girardin ha estudiado, con la penetración y la exactitud habituales en su crítica, el carácter de Porcia"] (Mézières, 1882: 438, nota 1).

${ }^{38}$ Parece que Darío/Blagenthal habían leído el segundo volumen de la novela Historia de un corazón de Emilio Castelar, publicado en 1874.

39 “Ce qui fait le principal intérêt de la pièce, c'est à coup sûr le portait du juif Shylock. Celui-ci est un type puissant qui représente tout un groupe d'individus" ["El interés principal de la pieza, sin duda alguna, reside en el retrato del judío Shylock. Es un tipo poderoso que representa toda una clase de individuos"] (Mézières, 1882: 165).

40 "L'auteur anonyme d'une exégèse anglaise de Shakespeare considère Iago comme le type de la race italienne. Ce n'est ni tout à fait juste ni surtout aussi neuf qu'il le croit. M. Macauley l'avait dit le premier et avec plus de mesure, dans son Essai sur Machiavel" ["El autor anónimo 
su religión, su lengua, su cultura y sus transformaciones... Una vez hecho esto, solo me restará completar mis conocimientos históricos relativos á Inglaterra cuya historia ha escrito Shakerpeare [sic] en parte sin quererlo, y dar principio á la redacción del libro.

[10] —De modo que ha leído usted para hablar de Shakespeare con conocimiento de causa y decirle al mundo espantado de tanta erudición lo que es ese genio casi único, millares y millares de volúmenes de todos tamaños?

[11] - Millares y millares de volúmenes...

[12] - Y á Shakespeare? lo habrá usted leído con especial atención.

[13] - Lo he hojeado algunas veces...

[14] Y el doctor Rapsodien de Blagenthal, haciendo otro gesto antiguo, después de estirarme fríamente la mano, salió estudiadamente envuelto en su imperturbable serenidad académica.

\section{Bibliografía}

Albala, Ken

"Shakespeare's Culinary Metaphors: A Practical Approach", en Shakespeare Studies. Madison, volumen 42 (2014), 63-74.

Arellano, Jorge Eduardo

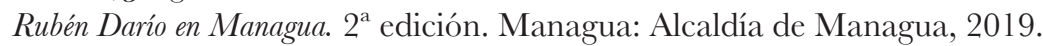

BARcia, Pedro Luis

"Shakespeare en la Argentina (Siglo XIX)", en Shakespeare en la Argentina. Contribución en el IV centenario de su nacimiento. La Plata: Universidad Nacional de La Plata, Facultad de Humanidades y Ciencias de la Educación, 1966, 41-97.

BüChNer, Alexandre

Hamlet le danois. Paris: Hachette, 1878.

DARío, Rubén

"Una nueva traducción del Dante”, en La Nación (28 de agosto de 1894), 1.

La caravana pasa. París: Garnier, 1902.

Parisiana. Madrid: Fernando Fé, 1907.

de una interpretación inglesa de Shakespeare considera a Iago como el tipo de la raza italiana. Eso no es ni completamente correcto, ni tan nuevo como se lo imagina. El señor Macauley fue el primero en afirmarlo, y lo hizo de manera más equilibrada, en su Ensayo sobre Maquiavelo"] (Mézières, 1882: 355, nota 1). 


\section{Equis [Rubén Darío]}

Todo al vuelo. Madrid: Renacimiento, 1912.

La vida de Rubén Darío escrita por él mismo. Barcelona: Maucci, 1915.

Obras desconocidas de Rubén Darío escritas en Chile y no recopiladas en ninguno de sus libros. Edición de Raúl Silva Castro. Santiago: Prensas de la Universidad de Chile, 1934.

Escritos inéditos. Recogidos de periódicos de Buenos Aires y anotados por E. K. Mapes. New York: Instituto de las Españas en los Estados Unidos, 1938.

Poesías completas. Edición, introducción y notas de Alfonso Méndez Plancarte. Madrid: Aguilar, 1952.

Escritos dispersos de Rubén Darío (recogidos de periódicos de Buenos Aires). Estudio preliminar, recopilación y notas de Pedro Luis Barcia. La Plata: Universidad Nacional de La Plata, Facultad de Humanidades y Ciencias de la Educación, 1968/1977, 2 tomos.

Prosas profanas. Prólogo de Guillermo Rothschuh Tablada. Managua: Distribuidora Cultural, 1984.

El viaje a Nicaragua e Intermezzo tropical. Edición de Fidel Coloma González y Pablo Kraudy. Managua: Nueva Nicaragua, 1987.

Azul... Managua: Nueva Nicaragua, 1988a.

Historia de mis libros. Managua: Nueva Nicaragua, 1988b.

El modernismo y otros ensayos. Selección, prólogo y notas de Iris M. Zavala. Madrid: Alianza, 1989.

Cuentos completos. Edición y notas de Ernesto Mejía Sánchez. Managua: Nueva Nicaragua, 1993.

España contemporánea. Edición, introducción y notas de Noel Rivas Bravo. Managua: Academia Nicaragüense de la Lengua, 1998.

Cartas desconocidas. Edición de Jorge Eduardo Arellano. Managua: Academia Nicaragüense de la Lengua, 2000.

Tierras solares. Edición, introducción y notas de Noel Rivas Bravo. Managua: CIRA, 2001.

Cantos de vida y esperanza. Los cisnes y otros poemas. Edición de Pablo Kraudy y Jorge Eduardo Arellano. Managua: Instituto Nicaragüense de Cultura, 2005.

Crónicas desconocidas, 1901-1906. Edición de Günther Schmigalle. Managua/Berlín: Academia Nicaragüense de la Lengua/Edition Tranvía-Verlag Walter Frey, 2006.

112 (an)ecdótica * vol. IV, núm. 2, julio-diciembre 2020 
Escritos políticos. Selección, estudios y notas de Jorge Eduardo Arellano y Pablo Kraudy Medina. Managua: Banco Central de Nicaragua, 2010.

Crónicas desconocidas, 1906-1914. Edición de Günther Schmigalle. Managua: Academia Nicaragüense de la Lengua, 2011.

Los Raros. Edición de Günther Schmigalle. Estudio preliminar de Jorge Eduardo Arellano. Berlín: Edition Tranvía-Verlag Walter Frey, 2015.

Novelas. Edición de Pablo Kraudy. Estudio preliminar de Jorge Eduardo Arellano. Managua: Banco Central de Nicaragua, 2017.

Freeman, Arthur y Janet Ing Freeman

Fohn Payne Collier: Scholarship and Forgery in the Nineteenth Century. New Haven: Yale University Press, 2004.

Fruman, Norman

Coleridge, the Damaged Archangel. London: Allen \& Unwin, 1972.

Gewecke, Frauke

"Ariel versus Caliban? Lateinamerikanische Identitätssuche zwischen regressiver Utopie und emanzipatorischer Rebellion", en Iberoamericana. Frankfurt, números 19/20 (1983), 43-68.

Groussac, Paul

Crítica literaria. Cervantes y el "Quijote"; la Gloria de Dante; al Romanticismo francés; Escritos de Mariano Moreno; Esteban Echeverría; Noticia sobre Tadeo Haenke; Tropezones editoriales; la Cuestión Shakespeare. Buenos Aires: J. Menéndez e hijo, 1924.

GutiérRez, Ernesto

"Rubén Darío y Shakespeare", en Revista Conservadora. Managua, número 87 (diciembre de 1967), 21-35.

Jáuregui, Carlos

“Calibán, ícono del 98. A propósito de un artículo de Rubén Darío”, en Revista Iberoamericana. Pittsburgh (julio-diciembre de 1998), 441-449.

LeFranc, Abel

Sous le masque de "William Shakespeare": William Stanley, VIe comte de Derby. Paris: Payot, 1918.

LOONEy, J. Thomas

"Shakespeare" Identified in Edward de Vere the Seventeenth Earl of Oxford. New York: Frederick A. Stokes, 1920.

Mejía SÁnchez, Ernesto

Cuestiones rubendarianas. Introducción, edición y notas de Julio Valle-Castillo. Managua: Fundación UNO, 2016. 


\section{MÉzières, Alfred}

Prédécesseurs et contemporains de Shakespeare. Troisième édition revue et corrigée. Paris: Hachette, 1881 [primera edición 1863].

Contemporains et successeurs de Shakspeare [sic]. Deuxième édition. Paris: Charpentier, 1864.

Shakespeare: ses cuvres et ses critiques. Troisième édition revue et corrigée. Paris: Hachette, 1882 [primera edición 1860].

PÉLADAN, Joséphin

La Queste du Graal: proses lyriques de l'éthopée "La Décadence Latine”. Paris: Chamuel, 1894.

Pongerville, Jean-Baptiste

Les femmes de Shakespeare. Paris: Gallet et Braud, 1880.

Prado, Edgardo

"La esposa nicaragüense de Rubén Darío", en La Prensa. Managua (7 de febrero de 1965), 1, 4-B.

Pujante, Ángel-Luis

Shakespeare en España. Textos, 1764-1916. Granada: Universidad de Granada, 2007.

Schmigalle, Günther y Rodrigo Caresani

Bibliografia de Rubén Dario en La Nación de Buenos Aires (1889-1916). Catálogo comentado y crónicas desconocidas. Managua: Dinámica, 2017.

Torres, Edelberto

La dramática vida de Rubén Darío. Edición definitiva, corregida y ampliada. San José, Costa Rica: Editorial Universitaria Centroamericana, 1980 (Colección Rueda del Tiempo). 